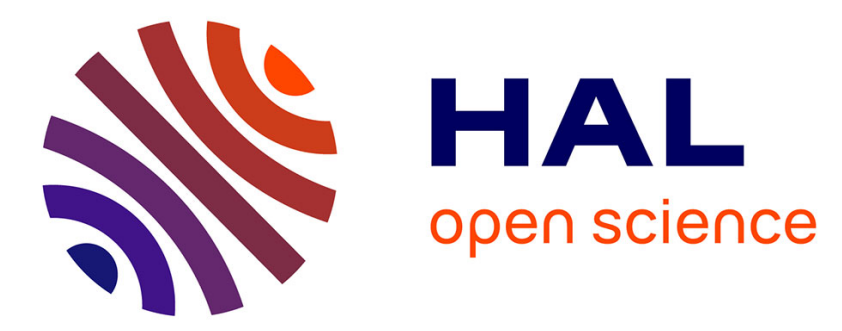

\title{
Effect of the plasticizer on permeability, mechanical resistance and thermal behaviour of composite coating films
}

Fabien Laboulfie, Mehrdji Hemati, Alain Lamure, Sylvain Diguet

\section{- To cite this version:}

Fabien Laboulfie, Mehrdji Hemati, Alain Lamure, Sylvain Diguet. Effect of the plasticizer on permeability, mechanical resistance and thermal behaviour of composite coating films. Powder Technology, 2013, vol. 238, pp. 14-19. 10.1016/j.powtec.2012.07.035 . hal-00926520

\section{HAL Id: hal-00926520 \\ https://hal.science/hal-00926520}

Submitted on 9 Jan 2014

HAL is a multi-disciplinary open access archive for the deposit and dissemination of scientific research documents, whether they are published or not. The documents may come from teaching and research institutions in France or abroad, or from public or private research centers.
L'archive ouverte pluridisciplinaire HAL, est destinée au dépôt et à la diffusion de documents scientifiques de niveau recherche, publiés ou non, émanant des établissements d'enseignement et de recherche français ou étrangers, des laboratoires publics ou privés. 


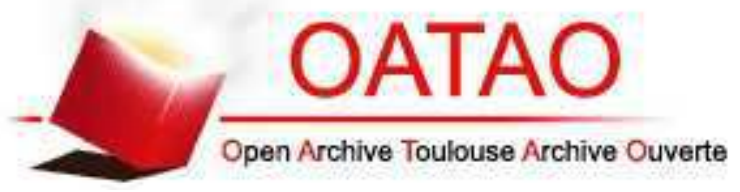

\section{Open Archive Toulouse Archive Ouverte (OATAO)}

OATAO is an open access repository that collects the work of Toulouse researchers and makes it freely available over the web where possible.

This is an author-deposited version published in: http://oatao.univ-toulouse.fr/ Eprints ID: 9934

To link to this article: DOI:10.1016/j.powtec.2012.07.035

http://dx.doi.org/10.1016/j.powtec.2012.07.035

\section{To cite this version:}

Laboulfie, Fabien and Hemati, Mehrdji and Lamure, Alain and Diguet, Sylvain Effect of the plasticizer on permeability, mechanical resistance and thermal behaviour of composite coating films. (2013) Powder Technology, vol. 238 . pp. 14-19. ISSN 0032-5910 


\title{
Effect of the plasticizer on permeability, mechanical resistance and thermal behaviour of composite coating films
}

\author{
Fabien Laboulfie ${ }^{\mathrm{a}, *}$, Mehrdji Hémati ${ }^{\mathrm{a}}$, Alain Lamure ${ }^{\mathrm{a}}$, Sylvain Diguet ${ }^{\mathrm{b}}$ \\ a LGC and CIRIMAT, 4, allée E. Monso-BP 4436231432 Toulouse (FR), France \\ b DSM, Nutritional Products Ltd Wurmisweg $576 \mathrm{CH}-4303$ Kaiseraugst (CH), Switzerland
}

\author{
Keywords: \\ Coating \\ Plasticizer \\ Water vapour permeability \\ Mechanical properties \\ Thermal behaviour
}

\begin{abstract}
A B S T R A C T
Thin layer deposit of a composite material on solid particle surfaces used in the food industry aims to ensure the protection of food powder against aggressive environments such as a moist atmosphere. The layer, having a thickness of a few fractions of millimetre, must have certain physico-chemical properties: it must be compatible with the product, it must be impermeable to water and oxygen, it must have good mechanical strength and good adhesion to the surface of the coated powder. Furthermore the layer must fulfil the regulatory requirements for food ingredients. Film properties like continuity, permeability, and mechanical resistance depend on the choice of the excipients included in the formulation and the operating conditions which can modify the constraints generated at the interface film-powder. As a consequence, the scientific issue consists of combining the local phenomena happening at a microscopic level on the surface of the particle with the processing technology and the process parameters. In a first step, the attention is focussed on the film and its formulation. For this step, films are prepared separately and they are dried under very smooth conditions. Test samples are taken from the formed composite films and contain hydroxypropyl methylcellulose as matrix (67\% of dried material), micronised stearic acid as hydrophobic filler ( $20 \%$ of dried material) and a plasticizer ( $13 \%$ of dried material). The film formation procedure and the test method are described in detail. The effect of the type of plasticizer (different grades of PEG) on mechanical, thermal and permeability properties of the coating film is studied. The results show that PEG with higher molecular rate provides a better plasticizing effect for the film but increases the water vapour permeability of the film.
\end{abstract}

\section{Introduction}

The coating process consists of making a deposit on the support (powder) of a solid layer with a few micrometres of thickness and whose permeability properties against water vapour transfer or oxygen ensure its protection. Depositing this film is done by spraying a liquid suspension on moving solid particles and by drying the coated powder with hot air flow. Coating processes are complex. They are constituted by the following consecutive elementary steps: mixing, spraying of the coating agent, wetting, coating of the surface and drying. The properties of the coated product are based on different parameters which are divided into four groups, namely: support properties, coating agent properties, coating machine technology and process parameters. The interactions between these different groups of parameters generate the complexity of the process. The properties of the coating agent (type, concentration, viscosity, surface tension liquid-vapour, wetting solidliquid) impact directly the particle size, particle size distribution, liquid distribution on the particle surface, film adhesion, drying speed and dry film properties (continuity, mechanical resistance, permeability). Thus, formulation steps of the coating agent are key parameters. The coating

\footnotetext{
* Corresponding author.

E-mail address: fabien.laboulfie@gmail.com (F. Laboulfie).
}

agent is made of film forming compounds (polysaccharides), which is the main component of the film network, associated with hydrophobic compounds (lipids) and with plasticizers to improve the mechanical properties of the film. These compounds are in an aqueous suspension. Among polysccharides, hydroxypropylmethylcellulose (HPMC) is one of the most widely used components in the food industry [6,7]. Indeed, according to [13], this compound has very good elasticity and film forming properties thanks to its long carbon chain structure. Moreover, HPMC is soluble in a wide range of solvents including water and ethanol. To reduce water diffusion through coating films, the most used components are long-chain fatty acids because of their high melting temperature and hydrophobicity [8,9,11]. In the work of [2], stearic acid (SA) is used as hydrophobic filler in modified cellulose based formulation. According to the work of [10], it is possible to formulate stearic acid and HPMC based coatings with equivalent or lower water vapour permeability than polyethylene films. Yet, an increase of the mass fraction of the stearic acid over 30\% weakens the film in terms of crack appearance. It is necessary to specify that film forming agents are water soluble whereas hydrophobic fillers are insoluble. Thus, formulation conditions of the coating agent impact the stability, the particle size and the particle size distribution of hydrophobic filler and modify the film properties [14]. In addition to film forming and hydrophobic compounds, the third component generally used is a plasticizer 
aimed at reducing the film stiffness by weakening intermolecular forces and improving the molecular chain mobility $[12,16]$. One of the most used plasticizers for pharmaceutical particle coating is polyethylene glycol (PEG) in hydrocolloid based formulation like gelatine [4] or methylcellulose films (Turhan et al., 2001). The influence of PEG and its grade on permeability and mechanical film properties in the ternary system HPMC/SA/PEG has not yet been studied systematically. Thus, the objective of this work is to study the influence of different grades of PEG (200, $600,1500,4000$, and 6000) used as plasticizer in composite HPMC based formulations, in which a hydrophobic filler has been dispersed. Measured properties are water vapour permeability, mechanical and thermal properties. This work presents an original method used to investigate films' plastic properties by working with interactions between formulation compounds through thermal properties of our coating films. Indeed, as in the works of [17], these interactions are usually measured with spectroscopy methods; we have decided to use DSC experiments to assess these interactions between film components.

\section{Materials and methods}

The works of [18] show that the stearic acid mass fraction increases until $20 \%$ inducing a significant reduction of gellan film water vapour permeability. Over this value, a high SA ratio (25\%) makes the film more brittle with crack appearance. So, the coating agents are formulated with an aqueous suspension of HPMC, stearic acid and plasticizer PEG by keeping the mass fraction of the stearic acid in the dried film constant at $20 \%$ to completely avoid crack possibilities due to high SA ratio. Table 1 presents the mass fraction of the different compounds used in the coating agent.

\subsection{Materials}

The hydroxypropyl methylcellulose (HPMC) used is food grade Methocel E19. This compound has a viscosity of $19 \mathrm{cp}$ in an aqueous solution at $2 \%(\mathrm{w} / \mathrm{w})$ and $25{ }^{\circ} \mathrm{C}$. The commercial SA used is actually a blend of stearic and palmitic acid (respectively $44 \%$ and 56\% of mass fraction). It comes in the form of a white cohesive powder which has a melting temperature of $55^{\circ} \mathrm{C}$. The different grades of PEG used are: $200,600,1500,4000$ and 6000 . These grades are functions of molecular weight. Grades 200 and 600 are viscous liquid at ambient temperatures whereas grades 1500,4000 and 6000 are white powders. Table 2 presents the melting temperature and aspect of the compounds used at the ambient temperature. In order to assess the influence of the PEG grade on the properties of the coating agent, we have decided to separately test coating layers from the coated particle by working on thin films realized from colloid suspensions. The next paragraph presents the casting protocol of composite films.

\subsection{Preparation and casting of composite films}

\subsubsection{Preparation of the suspension}

Aqueous polymeric solutions (pure HPMC or HPMC and PEG) have been formulated by dispersing HPMC and PEG in deionised water at $80{ }^{\circ} \mathrm{C}$ under agitation for $20 \mathrm{~min}$ followed by rest imposed on the solution at $25^{\circ} \mathrm{C}$ for $1 \mathrm{~h}$ to avoid all residual foam. Composite suspensions have been formulated by dispersing stearic acid in a solution of HPMC and PEG at $80{ }^{\circ} \mathrm{C}$ under agitation. Then stearic acid has been crystallized by cooling the suspension to ambient temperature. Suspensions have been finally degassed at 50 mbar for $1 \mathrm{~h}$. Particle size distributions

Table 1

Mass fraction of the different compounds in the formulation.

\begin{tabular}{lllll}
\hline & HPMC E19 & SA & PEG & Water \\
\hline Without plasticixer & $7.2 \%$ & $1.8 \%$ & - & $91 \%$ \\
With plasticixer & $6 \%$ & $1.8 \%$ & $1.2 \%$ & $91 \%$ \\
\hline
\end{tabular}

Table 2

Properties of used compounds.

\begin{tabular}{|c|c|c|c|c|}
\hline Compound & $\begin{array}{l}\text { Melting } \\
\mathrm{T}^{\circ} \mathrm{C}\end{array}$ & $\begin{array}{l}\text { Melting enthalpy } \\
(\mathrm{J} / \mathrm{g})\end{array}$ & Aspect & Origin \\
\hline HPMC E19 & - & - & Fine powder & $\begin{array}{l}\text { Dow chemical } \\
\text { company }\end{array}$ \\
\hline Stearic acid & 55 & 193.8 & Fine powder & MERK \\
\hline PEG 200 & -65 & - & Fluid & Fisher scientific \\
\hline PEG 600 & 22 & 128.8 & Viscous fluid & \\
\hline PEG 1500 & $43-46$ & 173.7 & Large crystal & \\
\hline PEG 4000 & $54-58$ & 199.6 & Large glitter & \\
\hline PEG 6000 & $56-63$ & 204.8 & Fines glitter & \\
\hline
\end{tabular}

have been measured with a Master Sizer (MALVERN). Visual observation and particle size distribution measurements of the rested suspension show that the coating agent is stable until film drying. Moreover, with formulation parameters and compounds used, PEG grade does not have any significant influence on the particle size distribution (Fig. 1). The same type of particle size distribution has been observed for other grades of PEG $(600,1500$ and 4000$)$.

\subsubsection{Preparation of films}

Aqueous formulations have been spread to form a $500 \mu \mathrm{m}$ thick film on a glass plate thanks to a manual hand coater and a $500 \mu \mathrm{m}$ fixed gate (TLC Plate Coater, hand operated, CAMAG, Muttenz, Switzerland). Films have been then dried for $24 \mathrm{~h}$ at $40{ }^{\circ} \mathrm{C}$ in an oven. Dry films have the following composition:

- Films without PEG: 80\% HPMC, 20\% stearic acid.

- Films with PEG: 67\% HPMC, 20\% stearic acid, 13\% PEG.

Film thicknesses have been measured with a vernier calliper $( \pm 1 \mu \mathrm{m})$. Six measurements have been done for each sample and the average has been calculated.

\subsection{Mechanical properties}

Films have been cut into rectangular samples (width: $20 \mathrm{~mm}$, working length: $80 \mathrm{~mm})$ with an average thickness of $60 \mu \mathrm{m}( \pm 10 \mu \mathrm{m})$. Samples have been stocked for $24 \mathrm{~h}$ at $40{ }^{\circ} \mathrm{C}$ in the dried atmosphere of an oven in order to avoid any mechanical property modifications due to the presence of water in the film. Tensile tests have been realized in dried atmosphere, with a static tensile test machine from Instron (Instron Instrument Ltd.). Strain speed applied during tests was $1 \mathrm{~mm} / \mathrm{min}$ until complete break of the test sample. Tensile strength (TS) and elongation at break (EB) have been measured during the

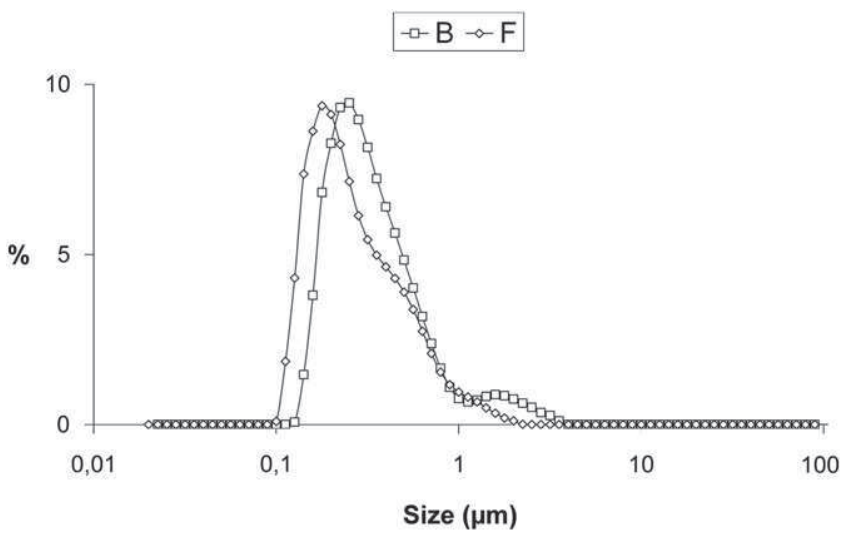

Fig. 1. Particle size distribution of stearic acid in the formulation. $B$ : HPMC $+S A+P E G 200$; F: HPMC + SA + PEG6000. 
test. Thanks to the initial slope of the tensile test graph, elastic modulus (EM) has been calculated with the Hooke's law (Eq. (1)).

$\sigma=\mathrm{E} \cdot \varepsilon$

With $\sigma$ as the stress applied to the film section $\left(\mathrm{N} / \mathrm{m}^{2}\right)$, E the elastic modulus $\left(\mathrm{N} / \mathrm{m}^{2}\right)$ and $\varepsilon$ the film strain $(\mathrm{m} / \mathrm{m})$. For each formulation, six samples have been tested; the average of the values has been calculated.

\subsection{Water vapour permeability (WVP)}

WVP of films have been determined according to the ASTM E96-01 method [1], widely used in the literature ([4,18]; Ayranci et al., 2000). Some changes have been made to measure the permeability of the film under more extreme conditions. Films have been sealed with a silicon ring on a cylindrical test bowl (inside diameter: $4.8 \mathrm{~cm}$, depth: $4 \mathrm{~cm}$ ). These bowls have been filled with $19 \mathrm{~g}$ of silica-gel previously dried for 7 days at $120^{\circ} \mathrm{C}$. This system sets the water activity to 0 in the atmosphere in contact with the film lower face. Bowls have been placed in hermetic desiccators at $40{ }^{\circ} \mathrm{C}$ in which an important volume of sodium chloride saturated solution sets the water activity. This system sets a water activity of 0.75 in the atmosphere in contact with the film upper face. With a $0.1 \mathrm{mg}$ precision balance, the water uptake of bowls has been measured each $24 \mathrm{~h}$ until a steady state was reached (constant change in weight).

Water vapour permeability of films (WVP) was calculated in the same way as $[3,5]$ with the following formula (2):

$W V P=\frac{\Delta m}{\Delta t} \times \frac{\mathrm{e}}{A \cdot \Delta P}$

with $\Delta m / \Delta t$ as the water vapour flux through the film in steady state (g/day), e thickness of the film ( $\mathrm{mm}), A$ film surface and $\Delta P$ water vapour partial pressure gradient.

\subsection{Thermal analysis}

The test objective was to understand the effect of interactions between the different compounds of the composite film on its degree of crystallinity. Thermal analyses have been realized thanks to a DSC test machine from TA Instruments. Samples have been produced by drying composite aqueous suspension in alumina test bowls at $25{ }^{\circ} \mathrm{C}$ for $24 \mathrm{~h}$. The reference used for the test was empty alumina bowls. Operating parameters have been calibrated as follows: one minute equilibrium at $-60{ }^{\circ} \mathrm{C}$ followed by a temperature ramp from $-60{ }^{\circ} \mathrm{C}$ to $90{ }^{\circ} \mathrm{C}$ with a heating rate of $15^{\circ} \mathrm{C} / \mathrm{min}$. Peak summit temperatures have been measured and melting enthalpies have been calculated by integrating the melting peak's area for each sample with the trapezoidal rule. This integration has been done between $20^{\circ} \mathrm{C}$ and $80^{\circ} \mathrm{C}$. Each sample has been tested three times and the average of values has been calculated. Experimental enthalpies measured with DSC have been compared with calculated theoretical enthalpy with the following method. By ignoring physical or chemical interactions between compounds and by only considering fusible compounds in the temperature test range; theoretical melting enthalpies were determined with a sum of pure compound melting enthalpies balanced by their mass fraction in dried films (formula 3). Reference values of crystalline parts melting enthalpies have thus been obtained by assuming that there is no interaction between the different compounds.

$\Delta H_{t h}=x_{S A} \cdot \Delta H_{S A}+x_{P E G} \cdot \Delta H_{P E G}$

with $\Delta H_{t h}$ as the theoretical melting enthalpy of the studied solid film, $x_{S A}$ and $x_{P E G}$ as mass rates of stearic acid and PEG in the formulation, and finally $\Delta H_{S A}$ and $\Delta H_{P E G}$ as melting enthalpies of pure $\mathrm{SA}$ and pure PEG compounds.

\section{Results and discussion}

\subsection{PEG grade effects on composite films mechanical properties}

Plasticizing effect of the PEG on mechanical properties of composite films is presented in the Figs. 2 and 3. Fig. 2 presents the effect of the addition and the grade of the PEG on the mechanical behaviour of films. It is observed that by comparing test A to other tests with PEG the addition of plasticizer reduces the elasticity of films and increases significantly the elongation at break (EB). This phenomenon is more important when the grade of PEG increased.

Fig. 3 shows that an increase of the PEG's grade induces a decrease of the TS for higher grades, and a decrease of the EM and an enhancement of the EB for all grades. The comparison between formulations with the plasticizer PEG (test B to F) and formulation without PEG (test A) shows that addition of PEG decreases the TS and EM but increases the EB. Fig. 3 shows that the addition of PEG increases the plastic behaviour of the films. The works of [4] on a binary system of gelatine and PEG (0.2 g PEG/g gelatine) shows similar trends. The addition of PEG in the gelatine induces a more plastic behaviour with drop of TS and EM and a rise of the EB. According to the work of [18], the addition of PEG in a gellan gum matrix induced greater mobility of the polymer chains by replacing polymer-polymer interactions by polymer-plasticizer interactions.

Even if we have the same trend with [4] about the addition of PEG in a hydrocolloid film, about the effect of the PEG's grade on the plastic behaviour of our films, these authors have yet observed opposite trends with their binary system of gelatine-PEG. That is to say that the rise of the grade of PEG induces an increase of the TS and the EM and a loss of EB. Authors have explained these trends in the work of [17] who have done a spectrophotometric study of hydrogen bonds in methylcellulose (MC) based films plasticized with PEG. According to these authors, modified cellulose presents many hydrogen groups $(-\mathrm{H})$ which can participate in hydrogen bonds and PEG is characterized with the rate of hydroxyl groups $(-\mathrm{OH})$ per mole. Yet this rate decreases with the rise of the PEG molecular weight, which reduces the number of hydrogen bonds between the molecule of PEG and the matrix of MC. Authors have explained that the polarity and the solubility of PEG is reduced by the increase of the grade because of the loss of the hydrogen bonds. Thus, an increase of the PEG grade reduces the capacity of this compound to interact and create bonds with modified cellulose chains. These conclusions have been deduced with a binary system (gelatine/PEG or MC/PEG), whereas our work is about ternary system (HPMC, SA, PEG). Our system contains stearic acid, a hydrophobic and nonpolar molecule. In our formulations, film mechanical properties depend on the SA inclusion in the HPMC matrix. An interface between SA and HPMC will improve this inclusion. As a plasticizer, it is the role of PEG. In this case, the decrease of the PEG's polarity with the increase of its

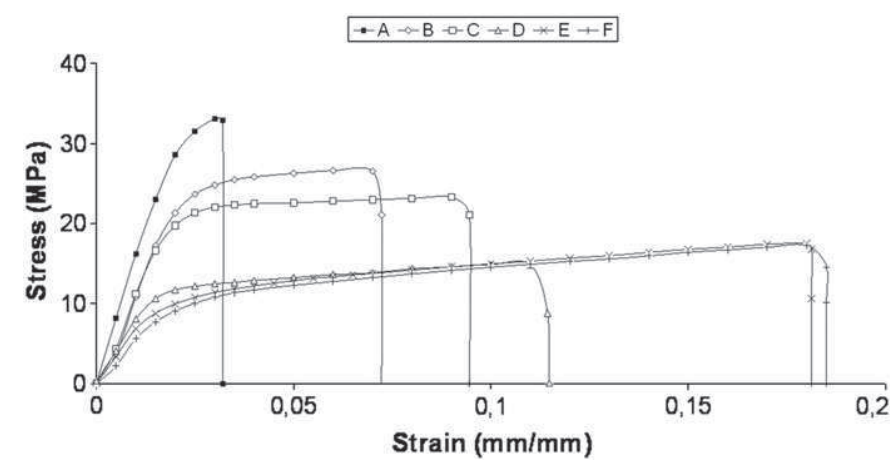

Fig. 2. Tensile tests of formulations. A: HPMC + SA; B: HPMC + SA + PEG200; C: HPMC + SA + PEG600; D: HPMC + SA + PEG1500; E: HPMC + SA + PEG4000; F: HPMC + SA + PEG6000. 

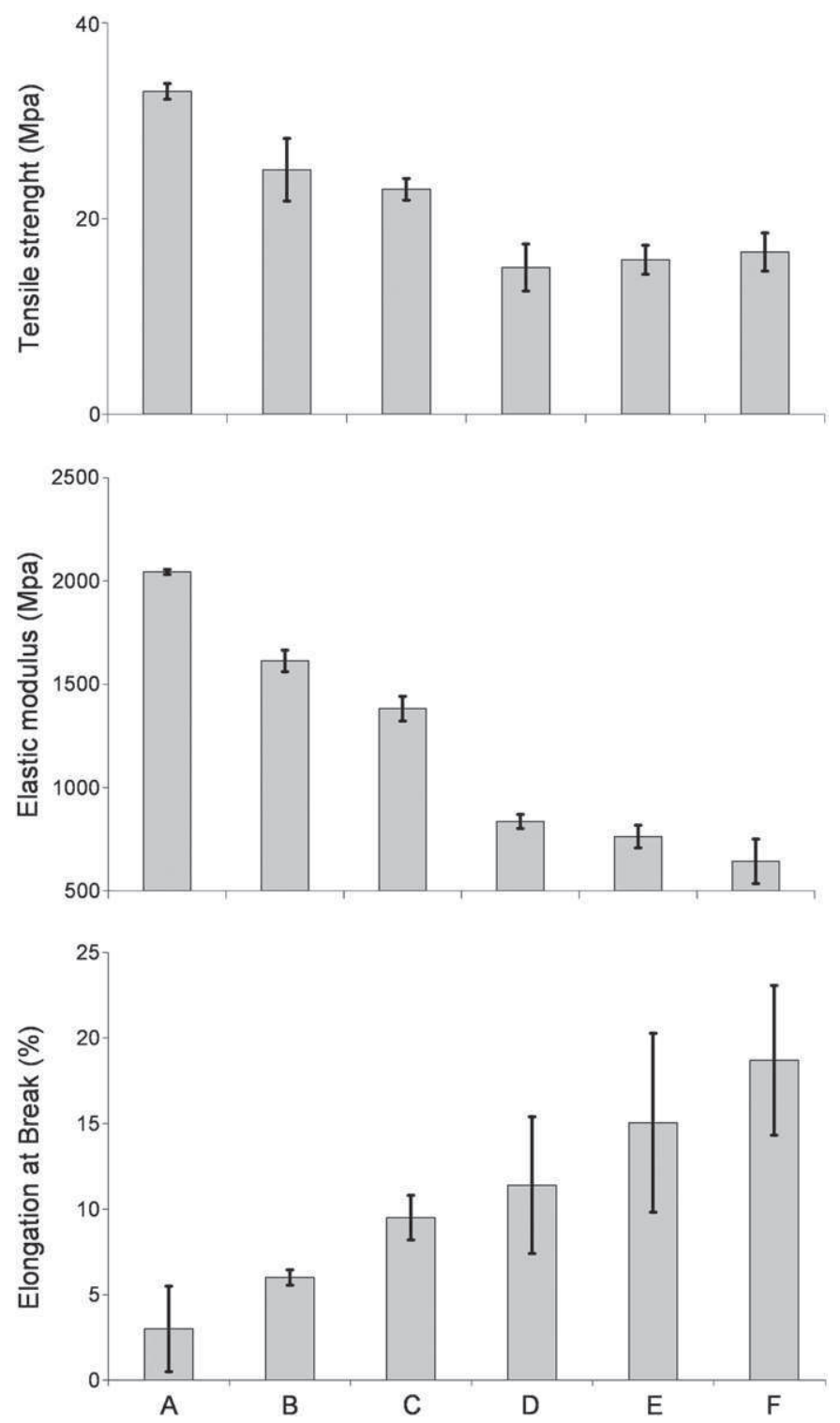

Fig. 3. Plasticizer effect of PEG on tensile strength (TS), elastic modulus (EM) and elongation at break (EB). A: HPMC + SA; B: HPMC + SA + PEG200; C: HPMC + SA + PEG600; $\mathrm{D}: \mathrm{HPMC}+\mathrm{SA}+\mathrm{PEG} 1500 ; \mathrm{E}: \mathrm{HPMC}+\mathrm{SA}+\mathrm{PEG} 4000 ; \mathrm{F}: \mathrm{HPMC}+\mathrm{SA}+\mathrm{PEG} 6000$.

grade could be the source of a stronger interaction with nonpolar stearic acid molecules. These interactions would permit the SA to be more deeply inserted into the polymer chains of the HPMC matrix by creating more important interfaces between HPMC and hydrophobic fillers of SA. Therefore, with three film components of HPMC, SA and PEG, addition of PEG provides a plastic behaviour to the film. This plastic behaviour is more important if the grade increases.

3.2. PEG grade effects on composite films water vapour permeability (WVP)

The effects of PEG on water vapour permeability of composite films are presented in Fig. 4. To compare our films with other materials, pure HPMC films WVP (Methocel E19) and low density polyethylene [15] WVP are displayed in the Fig. 4. The addition of SA in a HPMC based film reduces the WVP of the thin film. Yet, the addition of PEG presents two trends. For lowest grades of PEG (PEG200 and PEG600), addition of PEG reduces the films' WVP to comparable

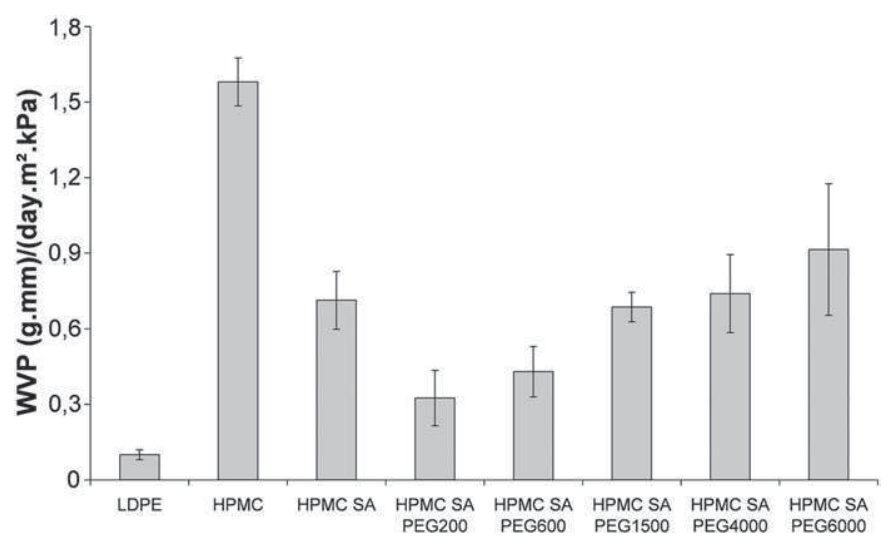

Fig. 4. Effect of the addition of PEG and its grade on WVP of films. LDPE: low density polyethylene; HPMC: Methocel E19; A: HPMC+SA; B: HPMC + SA + PEG200; C: HPMC + SA + PEG600; D: HPMC + SA + PEG1500; E: HPMC + SA + PEG4000; F: HPMC + SA + PEG6000.

values of LDPE. With the highest grades of PEG (PEG1500, PEG4000, PEG6000), an increase of the WVP of films is observed.

As explained in paragraph 3.1, PEG-HPMC interactions get weaker when the grade of PEG increases, which is beneficial to PEG-SA or PEG-PEG interactions. Two types of phenomenon can appear: micelle formation of PEG in the HPMC matrix, or PEG migration to hydrophobic fillers of SA. There is no conclusion as to which of the two phenomena is the predominant one but the heterogeneity of the film increases as the PEG's grade rises. According to the work of [14] on water vapour barrier properties of non-porous cellophane films coated with paraffin wax, it appears that the wax distribution was one of the major parameters of the barrier properties efficiency. Indeed, a non-uniform distribution would create favourite ways of water diffusion and thus would increase the WVP of films. The same trend is observed, and micelles formation in HPMC matrix and PEG migration to SA fillers can generate heterogeneity in the film. The increase of the PEG grade may induce a more localized distribution of PEG in the HPMC matrix and thus specify ways of water vapour diffusion.

\subsection{PEG grade effects on composite films thermal properties}

The effects of the addition of PEG and its grade on thermal properties of films are presented in Fig. 5. The first presents melting peaks of films. The addition of PEG reduced the melting temperature of films

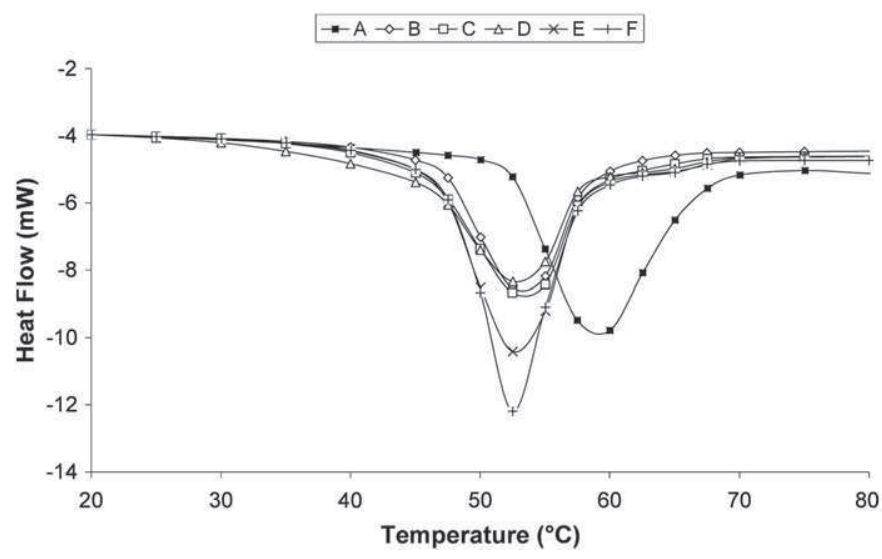

Fig. 5. DSC tests of the formulation. A: HPMC + SA; B: HPMC + SA + PEG200; C: HPMC + SA + PEG600; D: HPMC+SA + PEG1500; E: HPMC + SA + PEG4000; F: HPMC + SA+ PEG6000. 
but the peak summit temperature did not seem to be related to the PEG grade. Yet, peak area increased with the PEG grade.

Fig. 6 presents bi-components' formulation melting enthalpy as a function of the PEG grade. Discrepancies between theory and experiments should bring more information on PEG plasticizing effects. Indeed [4] have explained the plasticizing effect of the PEG in gelatine matrix by considering polyethylene glycol inclusion in the formulation through spectroscopy results of [17]. We have decided to use the same concept and have considered that plastic properties of our formulations are due to SA and PEG inclusions in the HPMC matrix. The chosen way to quantify this inclusion is the melting enthalpy measurements with DSC. As a matter of fact, by measuring experimental melting enthalpies of films and by comparing them to theoretical enthalpies, we can assess the SA and PEG crystallite inclusions in HPMC matrix.

Fig. 6 shows that in the temperature range imposed, HPMC E19 does not have a melting event. On one hand theoretical values show that addition of the lowest PEG grade (PEG 200) induces the appearance of a melting event. Theoretical enthalpy increases with PEG grade. DSC tests have shown that, instead of theoretical calculus, experimental tests do not present a melting event for grades 200, 600 and 1500

Fig. 6 also shows that experimental values are always inferior to theoretical calculus. Crystallite quantity is thus inferior to the expected value. A possible explanation is to say that interactions between HPMC and PEG are attractive and that PEG/HPMC interactions are predominant on PEG/PEG interactions. There is less opportunity to create PEG/PEG crystal in bi-component formulations (or not at all for lowest grade).

No melting event has been observed in the temperature range for lowest grade PEG 200, 600 and 1500 whereas for grade 4000 and 6000 , a melting enthalpy has been measured. As explained before PEG water solubility decreases with grade. Thus PEG 200 has higher water solubility than PEG 6000. A possible explanation of precedent results is to say that HPMC matrix, which is a hydrophilic material, acts as a solvent for PEG in the formulation. So as presented in Fig. 6, lowest grades of PEG are completely solubilised in the HPMC matrix. PEG is fully included in HPMC for the lowest grade.

On the other hand, for the highest grade (PEG 4000 and 6000), a crystalline part of PEG during DSC tests has been observed. But measured enthalpies are however lower than theoretical values because of the attractive nature of PEG/HPMC interactions. An explanation of this phenomenon may be that only a part of PEG has crystallised in the formulation and the other part is totally included in HPMC matrix as shown in Fig. 6. We can say that the quantity of PEG/HPMC interaction has reached a limit, a kind of limit concentration of PEG in HPMC, characteristic of PEG grade which leads to the presence of a crystalline part. If we compare both mechanical and thermal tests for bi-component formulation, the appearance of a crystalline part (with melting event)

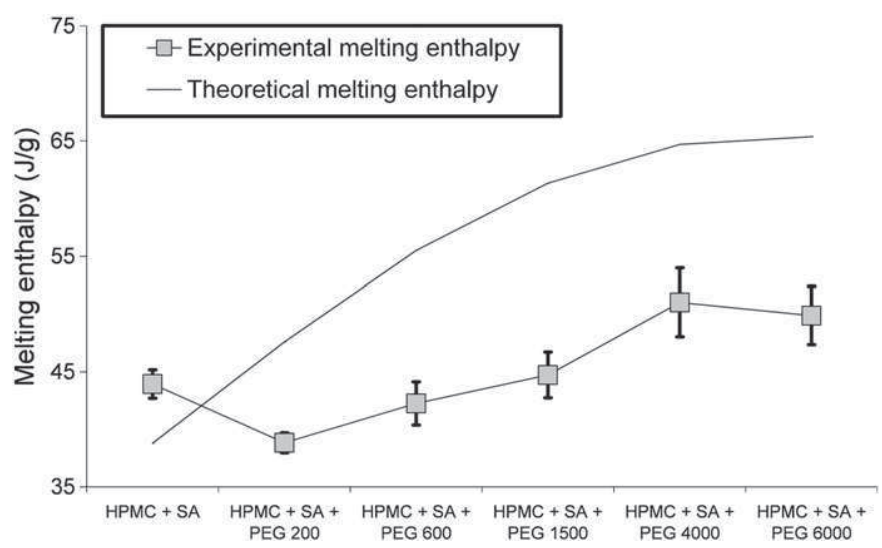

Fig. 7. Melting enthalpies of tri-component coating formulation. Comparison with theoretical enthalpies.

matches with the same grade (4000 and 6000) as a significant drop of elongation at break with tensile tests.

Fig. 7 presents composite formulation enthalpies as a function of PEG grade. The same method than before has been used by comparing experimental results to theoretical enthalpies calculated with a linear combination of pure product enthalpies weighted by mass fraction.

The formulation HPMC/SA theoretical values underestimate the experimental results. This indicates a repulsive interaction between SA (hydrophobic compound) and HPMC (hydrophilic compound) which induces a more important quantity of crystallite than expected in the formulation. This phenomenon is linked with the fact that to disperse SA in HPMC matrix, formulation protocol imposes to have a melted emulsion step. Indeed, the interaction SA/SA is stronger than the HPMC/ SA interaction which can cause the SA agglomeration.

But with the addition of a plasticizer PEG to final formulation (with a tricompound final formulation), experimental melting enthalpies for all different grades are inferior to theoretical calculus. A repulsive interaction between HPMC and SA for bi-components formulation has been observed whereas there are attractive interactions between SA and the complex HPMC/PEG. Moreover, even if the trend is not clear, it seems that the higher the grade is, the bigger is the difference between experimental and theoretical values. Thus, the higher the grade is, the more the PEG acts as an interface between HPMC and SA by minimizing $\mathrm{SA} / \mathrm{SA}$ interaction to the benefit of HPMC/SA/PEG interactions. Yet, this trend is not clear for intermediate grades (1500 and 4000).

Addition of PEG in the coating film induces a decrease of the melting peak summit. In another hand, an increase of PEG grade does not seem to have a significant influence on this temperature (Fig. 8). Thus, during the storage of coated product, storage temperature does not have to be

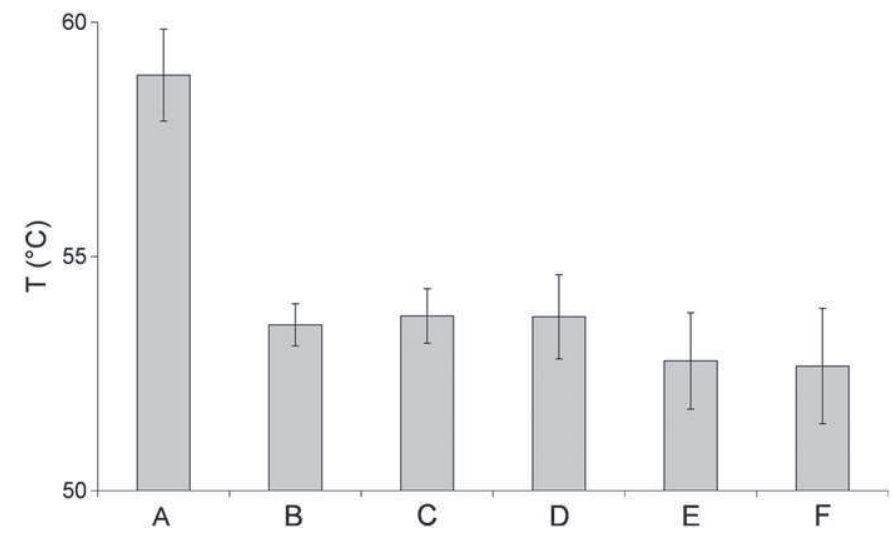

Fig. 8. DSC peak summit temperature as a function of $P E G$ grade. $A$ : $H P M C+S A$; B: HPMC + SA + PEG200; C: HPMC + SA + PEG600; D: HPMC + SA + PEG1500; E: HPMC + SA + PEG4000; F: HPMC+SA + PEG6000.
Fig. 6. Melting enthalpies of bi-component coating formulations. Comparison with the-

oretical enthalpies.

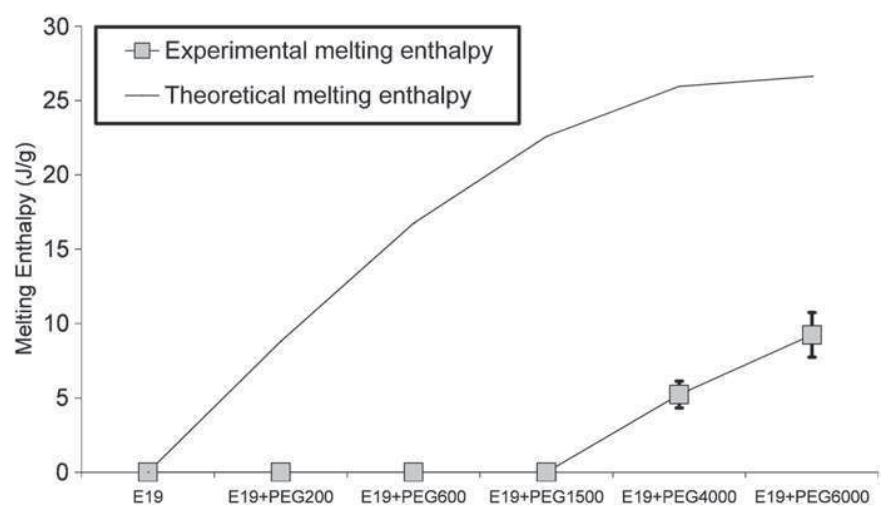


higher than the film melting temperature to avoid possible changes in the film morphology.

\section{Conclusion}

This work studies the influence of the plasticizer PEG grade on the properties of coating films made with HPMC E19, stearic acid and polyethylene glycol. The addition of PEG enhanced the plastic behaviour of films by reducing elastic modulus and tensile strength and by increasing elongation at break. Moreover, the rise of the grade of polyethylene glycol increased this trend. The addition of PEG reduced the WVP for grades lower than 600. It is thus necessary to find a compromise between, plastic properties, potentially useful to guarantee the continuity of the coating during industrial handling and WVP properties of films. The presence of polyethylene glycol in the formulation dropped the melting temperature. Melting temperature was not affected by the grade of the PEG but melting enthalpy increased with the polyethylene glycol grade. Finally DSC tests have permitted to bring some interpretation elements to assess interactions between film components through melting enthalpies measurement. Indeed these interactions and composite films mechanical behaviour are strongly linked by considering that plasticizer and hydrophobic filler inclusion in the polymeric matrix improve films plastic properties.

\section{References}

[1] ASTM, Standard test method for water vapor transmission of materials, in: ASTM Book of Standards, 1980, pp. E96-E.

[2] E. Ayranci, S. Tunc, The effect of fatty acid content on water vapour and carbon dioxide transmissions of cellulose-based edible films, Food Chemistry 72 (2000) 231-236.

[3] L.C. Bertan, P.S. Tanada-Palmu, A.C. Siani, C.R.F. Grosso, Effect of fatty acids and Brazillian elemi on composite films based on gelatine, Food Hydrocolloids 19 (2005) $73-82$.
[4] N. Cao, X. Yang, Y. Fu, Effects of various plasticizers on mechanical and water vapor properties of gelatin films, Food Hydrocolloids 23 (2009) 729-735.

[5] F. Debeaufort, A. Voilley, P. Meares, Water vapour permeability and diffusivity through methylcellulose edible films, Journal of Membrane Science 91 (1994) 125-133.

[6] E. Dinckinson, Hydrocolloids at interfaces and the influence on the properties of dispersed systems, Food Hydrocolloids 17 (2003) 25-39.

[7] E. Dinckinson, Hydrocolloids as emulsifiers and emulsion stabilizers, Food Hydrocolloids 23 (2009) 1473-1482.

[8] S. Guilbert, Technology and application of edible protective films, in: M. Mathlouthi (Ed.), Food Packaging and Preservation. Theory and Practice, Elsevier Appl. Sci. Publ. Co, London, England, 1986.

[9] R.D. Hagenmaier, P.E. Shaw, Moisture permeability of edible films made with fatty acid and (hydroxypropyl)methylcellulose, Journal of Agricultural and Food Chemistry 38 (1990) 1799.

[10] S.L. Kamper, O.R. Fennema, Use of edible film to maintain water vapor gradients in foods, Journal of Food Science 50 (1985) 382-384.

[11] J.J. Kester, O.R. Fennema, Edible films and coatings: a review, Food Technology 40 (12) (1986) 47.

[12] J.J. Kester, O.R. Fennema, The influence of polymorphic form on oxygen and water vapor transmission through lipid films, Journal of the American Oil Chemists' Society 66 (8) (1989) 1147.

[13] K.L. Krumel, T.A. Lindsay, Nonionic cellulose ethers, Food Technology 30 (4) (1976) 36-43.

[14] M. Martin-Polo, C. Mauguin, A. Voilley, Hydrophobic films and their efficiency against moisture transfer. 1. Influence of the film preparation technique, Journal of Agricultural and Food Chemistry 40 (1992) 407-412.

[15] S.A. Smith, Polyethylene, low density, in: The Wiley Encyclopedia of Packaging Technology, M. Bakker, John Wiley \& Sons, 1986, pp. 270-275.

[16] P.C. Srinivasa, M.N. Ramesh, R.N. Tharanathan, Effect of plasticizers and fatty acids on mechanical and permeability characteristics of chitosan films, Food Hydrocolloids 21 (2007) 1113-1122.

[17] K.N. Turhan, F. Sahbaz, A. Guner, A spectrophotometric study of hydrogen bonding in methyl cellulose based edible films plasticized by polyethylene glycol, Journal of Food Science 66 (2001) 59-62.

[18] S. Yang, A.T. Paulson, Mechanical and water vapor barrier properties of edible gellan films, Food Research International 33 (2000) 563-570. 